\title{
History of health technology assessment in Sweden
}

\author{
Egon Jonsson \\ University of Alberta and University of Calgary and Institute of Health Economics
}

\section{HISTORY OF HTA IN SWEDEN}

\section{Environment for Healthcare Assessments in Sweden}

Sweden has a long history of using data as a basis to form policies in many sectors of society. The very first documented efforts to collect data and use some kind of evidence to judge health care began 350 years ago in Sweden. In 1663, the Swedish Collegium Medicorum (re-named Collegium Medicum in 1688) was established; initially to distinguish quackery from medicine, to develop a pharmacopoeia, to control the trade of poisonous drugs, and banish all swindlers who "grease people with their fake, fraudulent, and harmful medicaments"( $12 ; 20 ; 25 ; 26)$.

Eventually, the Collegium came to act on disciplinary issues, monitor the work of doctors, midwifes, and pharmacists, influence the education and examination of doctors, and represent state interests in the health of the population. The Collegium required yearly reports from district physicians, "who described the disease profiles of local areas, the level of medical treatment and drug therapy available, as well as the lifestyles of the population; nutrition, housing conditions, levels of alcoholism and literacy...", including information on treatments provided, along with crude outcome measures such as "improved" or "deceased" (20).

In 1813, the Collegium became a department of the civil service named The Royal Health Board (Sundhetsstyrelsen) and had greater authority over the provision of health care. However, from 1797 to 1876, the monitoring of hospitals remained with an aristocratic institution named Serafimerordensgillet.

Important bodies in the state administration in Sweden were the County Administrative Boards (Lansstyrelser), established in 1634, in twenty-five regions and some major cities across the country. Initially, their most important tasks were to maintain law and order and to see to it that taxes were raised appropriately. There were, however, no locally based institutions that could balance these state bureaucracies' influence on issues regarded as domestic. As a result of continued demands to the Parliament for increased local authority and decision making, the government created locally elected governing bodies in each of the twenty-five regions and cities. The main responsibility for the operation of health care was handed over to these newly formed County Councils in 1864 . The Councils were later allowed to levy taxes locally to pay for health care in their region (1).

Nevertheless, the Government maintained substantial supervisory and monitoring control of health care by merging the Collegium and a few other departments into a fullscale agency in 1878, named the National Board of Health (Medicinalstyrelsen). It was given strong authority, including all mandates of the former Collegium, (e.g., examinations and the supervision of all healthcare workers in medicine, pharmacy, dentistry, nursing, and midwifery). It also monitored vaccination programs, forensic medicine, veterinary medicine, hospitals, and other institutions for somatic and mental health care, and all health care for personnel in the army and navy. This agency also became the supervising body for the medical schools and the county councils. It kept numerous types of records containing data of importance for analyzing how the health services might be improved.

In 1912, the parliament passed legislation on another agency, the National Board of Social Affairs, to coordinate new and existing social issues that several different ministries dealt with previously, for example, labor market regulations, inspections, health prevention for workers, social insurance, and care of the poor and vulnerable children. This agency was also mandated to initiate an effective temperance movement in the country. During the 1930s and 1940s, many emerging social issues were to become important areas for the new agency: care centers, playschools, charity homes, and summer camps for children. A specific problem that the agency had to address was housing for the great number of refugees that entered the country during the Second World War. Later, it had to take on many more responsibilities, such as the administration of government subsidies for students in higher education, mandatory pension funds, care of the elderly, long-term care, and social services at home. 
In 1958, the supervision of medical and social welfare services were unified by merging the medical and social boards into a single agency, the National Board of Health and Welfare (NBHW), currently the major agency for healthcare services in Sweden. A few years earlier (1955), the national health insurance program that the parliament had legislated in 1945 was put into effect. An important reform to control the diffusion of expensive and sophisticated technology was put in place in 1958 when highly specialized services were regionalized into seven regions. Each region would have a regional hospital with the capacity to address rare and complicated cases of disease and trauma. These regional hospitals would, in principle, be the first to be equipped with modern, capital-intensive medical technology, for example, transplantation services and burn care.

Sweden's long history of agencies and institutions in health care naturally included some forms of assessment of health practices, procedures, programs, and technologies. Those were certainly not as rigorous, systematic, widespread, and common as the ones in place today. The basic tools of health technology assessment (HTA) were simply not available until much later. Databases of scientific studies first became available in the late 1960s, and personal computers and the Internet were not available until the 1980s and 1990s.

A brief overview of the current Swedish healthcare system is available at http://www.sweden.se/eng/Home/Worklive/Society-welfare/Health-care/Facts/Swedish-health-care/ (26).

\section{Development of HTA in Sweden During the 1970s to Mid-1980s}

Although the history of HTA in Sweden is strongly linked to the establishment of a national agency in 1987, the Swedish Council on Technology Assessment in Health Care (commonly known by its Swedish acronym $S B U$ ), other initiatives, organizations, and institutions historically played an important role in the development of HTA in Sweden.

Several actions were taken toward assessing health practices and procedures long before formal systematic reviews, evidence-based medicine (EBM), and HTA became established concepts in the country. Most agencies and institutions in Swedish health care participated in these activities one way or another. These included NBHW, the Federation of Swedish County Councils (now the Swedish Association of Local Authorities and Regions, SALAR), the Medical Research Council, Spri (see below), the Swedish Society of Medicine (Lakaresallskapet, a scientific society for physicians established in 1808), the Swedish Medical Association (Lakarforbundet, a professional labor union for physicians established in 1903), and many individuals from the clinical and health services research community.

From the 1960s onward, the NBHW managed a program of broad-based assessment of new innovations in health care to determine whether these were "consistent with proven scientific knowledge and good experience." Teams of selected experts were consulted on technology-related matters of particular relevance to regional hospitals in the country. The assessments were based on findings from clinical research. Using these findings and other data, for example, demographics and current disease panoramas, the NBHW calculated and projected healthcare needs. In a relatively transparent manner, the teams presented their reasoning behind what they believed would be the appropriate level of use of these technological innovations. As a rule, these assessments did not focus on any individual technology, but usually covered a whole spectrum of technologies necessary to deal effectively with the need, for instance in radiation therapy, thoracic surgery, neurosurgery, and specialized cardiac care.

In 1968, the government and the county councils established an independent agency named the Swedish Planning and Rationalization Institute for the Health Services, (Spri). Spri was mandated to address the effectiveness of health services in the broadest possible sense. Spri's program initially included issues of architectural design of hospitals, ventilation and other engineering issues concerning hospital buildings, ambulance equipment, classifications, staffing analyses, and organization of services. However, as the agency quickly expanded, it soon entered many other fields of health care, for example, health planning, assessment of medical technology, development of guidelines, cost-effectiveness analyses, and analyses of variation in health practices. The institute often worked in close collaboration with the NBHW, the Federation of Swedish County Councils, the Swedish Medical Association, and eventually with the Medical Research Council of Sweden. In 1974, researchers at Spri performed one of the first assessments of the computed tomography (CT) scanner (14) and later collaborated on that subject with Barbara McNiel, a radiologist at Harvard University, who was a very strong proponent for HTA in the United States.

In 1975, the NBHW, in collaboration with the Swedish Society of Medicine, began to establish national quality registers for certain procedures. A cancer registry had been established already in 1958. These registries, now approximately fifty in total, have become important tools for measuring both technical capabilities and patient outcomes, including health-related quality of life, related to using specific healthcare technologies.

Around the same time, the Federation of the County Councils, the NBHW, Spri, and the Swedish Medical Association launched an ambitious program to provide training for all senior clinicians in the country in administrative and economic aspects of health care. That program, known as $F A L$ (continuing education in administration for physicians) continues today, albeit in different forms in different county councils and not as a national program. The aim was to provide basic training in organization, administration, planning, human resources, epidemiology, and health economicsincluding evaluation of medical practices and technologies. It contained much of what is now called evidence-based 
medicine. The FAL program operated regionally throughout Sweden for all interested clinicians. In reality, it became more-or-less compulsory to pass the 3-week course, especially for anyone intending to become a chief of clinical services. This extensive program laid the groundwork for events to come related to HTA in Sweden.

In the mid-1970s, Spri and the NBHW jointly took another initiative, also oriented toward assessing health practices. That initiative called for the development of national guidelines (vardprogram), which laid the foundation for a later, more structured and well-coordinated program to develop national guidelines, now managed by the NBHW. The current guidelines include not only findings from clinical research and HTA, but also analyses of ethical implications, equal accessibility to services, and consideration of the Parliament's priorities for health care (32).

In the early 1980s, Spri and its counterparts in Denmark (Danish Hospital Institute), Finland (Finnish Hospital League), Norway (Norwegian Hospital Institute), and later with representation also from the Ministry of Health in Iceland, initiated discussions about collaboration in medical technology assessment. Eventually a collaborative body known as NEMT (Nordic Evaluation of Medical Technology) was established and began working on issues concerning appropriate diffusion and use of technologies such as MRI, prostate cancer screening, and coronary bypass surgery. Independent of NEMT, Spri conducted several assessments of MRI at that time (28).

In 1979, Spri sponsored the first European Conference on Medical Technology Assessment. The conference was organized by Egon Jonsson, Melinda Ojermark, and Lars-Åke Marké and was chaired by Tore Schersten. Among others, David Banta and Johannes Vang participated as speakers. Approximately thirty-five people from throughout Europe and the United States, and representatives from the World Health Organization (WHO), participated in the conference (13). It was followed a few years later, in 1982, by a workshop on HTA, also organized by Egon Jonsson and chaired by Tore Schersten. This 3-day workshop was held on the island of Uto in the Stockholm archipelago. One item on the agenda addressed how to organize HTA at the national level in Sweden. Approximately thirty people from the United States and Sweden participated, among them a hospital director from the city of Linkoping, Orvar Steehn, who, in collaboration with his assistant Per Carlson, had shown an interest in the subject for quite some time. Per Carlson later came to work for SBU to build its program for rapid assessments of emerging technologies. Orvar Steehn brought the idea of HTA to the chair of his local county council, Ragnar Gustafsson, who shortly thereafter contacted Jonsson and Schersten to assist in drafting a proposal to set up a center for medical technology assessment in that county. The County Council also sponsored a study tour to visit organizations in the United States dealing with medical technology assessment, in particular the Office of Technology Assess- ment (OTA). The study group included the dean of the medical school in Linkoping, and a representative of the County Council, along with Steehn, Jonsson, and Schersten. This effort led to a more fully developed proposal in 1983 from those in Linkoping to set up the Center for Medical Technology Assessment (CMT).

Bengt Jonsson, who was appointed as Sweden's first professor of Health Economics at Linköping University in 1982, was called on to establish and manage the Center. He had been involved in HTA for several years, as Associate Professor at the Department of Economics at Lund University and later head of the Institute of Health Economics in Lund, and also as an adviser to OTA on methods for cost-effectiveness analysis in HTA. He organized the Center as an independent research institute within Linköping University but supported financially by the local County Council. CMT started its work in 1984 and remains active today. It has produced many assessments addressing prevention, medical devices, procedures, pharmaceuticals, and other health technologies. CMT students have produced many dissertations in the field of HTA. Bengt Jonsson eventually moved to the Stockholm School of Economics and built the Center for Health Economics, including a unit for HTA. Its staff frequently participates in SBU projects, and Bengt Jonsson served on the SBU Scientific Advisory Committee for 15 years, from 1987 through 2002.

Although the need for a national mechanism for HTA was discussed during this period, the establishment of SBU was still some years in the future.

\section{People in the History of Establishing SBU in Sweden}

Sweden has a long tradition of strong and independent governmental institutions. The following historical narrative of HTA in Sweden, however, focuses more on individuals than on institutions. Such an approach is relevant in the context of the trust that Swedish citizens have in their government. Ultimately, this trust is a reflection of objective and reliable performance by the individual civil servants appointed to manage public agencies, develop policy proposals, and monitor policies once they are implemented.

History is made by people and the opportunities they seize. Many individuals in the clinical research community and in the agencies and institutions mentioned in the preceding section actively endorsed the idea to pursue critical, unbiased review of the evidence base for health technologies and to enlighten the implications of technological advancements from a policy perspective.

Among those in Sweden who made substantial contributions to this effort in the late 1970s and well into the 1980s were Tore Schersten and Henry Danielsson of the Medical Research Council, Egon Jonsson from Spri, and later, Bo Holmberg, chair of Vasterbotten County Council 
(northern Sweden) who would become a Cabinet Minister in the Swedish Government.

Tore Schersten, Professor of Surgery, was dean of the medical faculty at the University of Gothenburg and later president of the Swedish Medical Research Council. He played a key role in getting HTA on the Swedish Government's agenda. Without his respectability and influence at the highest level of health policy making, and without his strong personal efforts and convictions about the need for EBM and broad-based assessment of medical practices, procedures, and technologies, HTA in Sweden probably would have had to wait much longer before acquiring sufficient interest for the Government to establish an HTA agency. Schersten eventually convinced the Minister of Health and the Minister of Civil Affairs that the Government ought to appoint a committee to investigate the potential benefits of establishing an agency for HTA. He later chaired the Scientific Advisory Committee of SBU and was elected President of the International Society for Technology Assessment in Health Care (ISTAHC). Tore Schersten has served on the Editorial Board of the International Journal of Technology Assessment in Health Care since its launch in 1985.

Henry Danielsson chaired the Medical Research Council (now part of the Swedish Research Council), one of the most respected healthcare institutions in Sweden at the time. He contributed greatly to health services research in general and to health technology assessment in particular. Schersten and Danielson approached Spri early in the 1980s to launch Sweden's Consensus Development Conferences, modeled after the program at the National Institutes of Health in the United States. That program started in 1981 and continued for nearly 20 years in Sweden. It played a profound role in bringing scientific findings to audiences beyond the research community. In addition, it indirectly fostered much wider recognition of the need for more clinical research to strengthen the evidence base in medicine. Danielson later became active in ISTAHC and collaborated with Johannes Vang and Itzhak Jacoby (head of the consensus program at $\mathrm{NIH})$ to produce a special section of the Journal on the subject of Technology Assessment and the Alteration of Medical Practices. Danielsson also served on the Editorial Board of the Journal for many years.

Another individual who played a notable, historic role in the early 1970s was Johannes Vang, a surgeon from Lund University and the Eksjo Hospital. Johannes Vang contributed more than any other single individual to the abovementioned FAL courses for training clinicians in aspects of EBM. Johannes Vang later accepted a position as regional advisor on health technology assessment at WHO. He was a founding member of ISTAHC and arranged its first meeting, held at WHO in Copenhagen in 1985. He also served on the Editorial Board of the Journal for many years.

Duncan Neuhauser from Harvard School of Public Health had visited Sweden regularly since the early 1970s, generating further interest in HTA among Swedish re- searchers (9). In 1973, he introduced the author of this study to key figures at the Harvard Center for the Evaluation of Clinical Procedures, among them Howard Hiatt, Harvey Fineberg, Milton Weinstein, William Stason, and Fred Mosteller. These individuals, and their new ideas about the need for broad-based assessment of health practices, had a substantial impact on later events along the road toward forming a national agency for HTA in Sweden. Duncan Neuhauser has served on the Editorial Board of the Journal since 1985.

Another key role in the history of HTA in Sweden was played by David Banta, then a young researcher at OTA (Office of Technology Assessment at the U.S. Congress). He visited Sweden frequently and stayed for long periods during the late 1970 s and early 1980 s. He co-authored several publications on health technology assessment in Sweden (16). Banta served as a consultant on many of SBU's projects for nearly a decade, and on the Editorial Board of the Journal since its inception.

\section{Establishment of SBU}

The first critical and sustained discussion on establishing a Swedish health program similar to OTA took place in 1981 at a conference arranged by Vasterbotten County Council. The conference included an assessment of the appropriate diffusion and use of CT scanners in that county. The county council's chairman, Bo Holmberg, immediately realized the potential of health technology assessment and initiated a discussion with conference speakers Schersten and Jonsson about a possible agency for HTA in Sweden. One year later, Bo Holmberg became the Minister of Municipal Affairs in the Swedish Government. In 1984, then as Minister of Civil Affairs, he called on Schersten and Jonsson to discuss how a potential HTA agency could be organized. Holmberg discussed this further with the Minister of Health, Gertrud Sigurdsen, and both participated in several informal meetings with an extended group of potential stakeholders in the field.

As a result of many meetings on HTA - not least a conference held in the Government's offices that involved the Minister of Finance, Kjell Olof Feldt, who was supportive of HTA - the Minister of Health decided in 1985 to appoint a Committee to review and propose how HTA could be organized at the national level in Sweden. Because several agencies, for example NBHW and Spri, had a strong interest in the matter it was important to review the benefits of incorporating HTA into their existing programs compared to establishing a new, independent national mechanism for HTA. The Committee agreed that it would be most beneficial to establish an independent agency. Thomas Luttropp, Assistant Undersecretary at the Ministry of Health, chaired the Committee comprised of representatives from the NBHW, Spri, the Society of Medicine, the Medical Association, the Medical Research Council, and the Federation of Swedish County Councils.

This Committee worked during a period when the Government was making substantial cutbacks in nearly every 
agency in Sweden. Prospects were indeed unfavorable for establishing a new agency. Nevertheless, a proposal was finished in 1986 to establish a national forum for HTA in Sweden, independent of the agencies and institutions represented on the Committee. Luttropp managed, against all odds, to negotiate with the Ministry of Finance a fairly substantial budget for the agency. That achievement also reflected a strong signal that the Minister of Finance viewed HTA to be important for the country. In 1987, the Minister of Health formally established and funded the Swedish Council on Technology Assessment in Health Care (Statens Beredning for Utvardering av Medicinsk Teknologi, SBU).

On several occasions, the Committee discussed the selection of an individual to chair the SBU Board. Those discussions revolved around the fact that SBU would have no regulatory power, and that for the next several years clinicians in particular would have little, if any, incentive to use the findings from a totally unknown organization dealing with a somewhat unknown subject-HTA. The Committee realized that the only workable strategy to establish a link between HTA's evidence-based findings and the actual use of those findings would be to build a strong collaboration with the medical profession and develop a level of trust in SBU that its findings would be viewed as an integral and fundamental part of professional practice. Clearly, several members of the Committee, for instance Schersten, Danielson, and Thomas Ihre (then chair of the Medical Association), possessed the qualities needed for this task. However, the Committee agreed that a nonmember-an individual recognized as having the highest possible integrity and trust among medical and managerial communities-must be found to chair the Council. The Committee produced a list of potential candidates, and the Committee chair proposed to the Minister of Health that Lars Werko be appointed to chair SBU.

Lars Werko was an icon among respected citizens in Swedish society. He was a former professor and highly regarded clinician of medicine from the University of Gothenburg, former head of the Medical Association, former long-standing member of the Medical Research Council, former head of research, and deputy CEO of Astra, a major Swedish pharmaceutical corporation. His reputation was well established in the international community of scholars. He was a well-known debater, frequently publishing critical and polemical articles on issues in health care. Werko was to become a full-time working chair of SBU for 10 years, while Schersten served as chair of the Scientific Advisory Committee for 5 years, after which he became chair of the Medical Research Council. Werko continued to serve SBU as a staff member for another 5 years. In this context, it can be mentioned that the full Swedish name given the Council was rather cumbersome, and finding an acronym was a topic of much discussion. In an interview by the Journal of the Swedish Medical Association, Lars Werko simply used SBU as if that were the most appropriate and natural acronym.
After his statement, there was no need to discuss the matter further.

The choice of Werko to chair the Board and Schersten to chair the Scientific Advisory Committee, and the careful selection of influential people to SBU's Board and Scientific Advisory Committee were essential to the success of the organization. It survived its first few fragile years well and quickly built strong trust throughout the communities of researchers, clinicians, managers, and policy makers. Contributing to this was the fact that, from the outset, SBU never ran its projects in isolation from the groups it intended to impact. Project teams were always composed of leading experts from outside of the organization. SBU also selected pertinent topics for assessment, which demonstrated the potential of HTAs. Another key feature that heightened the appreciation for SBU was that it did not focus only on individual technologies but assessed entire health topics, simultaneously evaluating all diagnostic and treatment technologies used in the area studied, for example, radiotherapy, alcohol and drug abuse, urinary incontinence, back pain, and depression. From the outset, SBU actually did what is frequently called for today, namely Comparative Effectiveness Analyses. Early on, and repeatedly, SBU recommended that many promising technologies which lacked a good evidence base should be used only within research projects, that is, what is now referred to as Coverage with Evidence Development.

\section{SBU: The National Agency for HTA in Sweden}

The Government's main incentives for establishing SBU included (i) a concern about the increasing cost of health care; (ii) a need to speed up the diffusion and use of new, effective, and cost-effective technology to increase access and quality of care; and (iii) to obtain reliable scientific information on the value of established and new technology in medicine as a basis for potential disinvestment and priority setting in health care.

Briefly, the Government's instructions to SBU in 1987 were as follows: The agency must provide evidence-based information on matters of health technology to advise health policy and practice and to inform the general public. It would have no regulatory function. It was made explicit from the outset that the agency must synthesize research findings and present this information in a manner understandable even to the interested general public. The agency should focus on not only the medical aspects, but also on the economic, ethical, and social implications of different technologies, procedures, and programs for prevention, diagnosis, and treatment of disease and disability. Its functions should include measures for effective dissemination and impact of findings from research. The Government's instructions to SBU are not much different today: "SBU is mandated to make scientific assessments of new and established health technologies from a medical, economic, societal, and ethical perspective. The agency shall 
present and disseminate these assessments so that providers of health care and others may be able to use the findings of the assessments. The agency shall assess how the findings have been used and what results have been achieved" (7).

SBU became operational in 1987 with two staff members: its first and longstanding CEO Egon Jonsson and his secretary Christina Engstrom, both from Spri. Engstrom came to play a role far beyond that of a secretary, as she quickly grew into an effective manager who handled a myriad of matters in essentially all projects, scheduled all of SBU's other activities, and thereby became the nucleus of the organization. The CEO and the members of the Board and Scientific Advisory Committee had contact with extensive national and international networks of researchers in the field. After SBU's second year of operation, the Government, through the chair of the Federation of the County Councils at the time, Bengt Holgerson, formally assessed the agency (29). The outcome of this assessment was highly positive and resulted in establishing SBU as a permanent agency.

SBU now employs more than forty full-time staff members and engages several hundred researchers, clinicians, managers, and policy makers throughout Sweden who are active in different aspects of its work. In 2003, Nina Rehnqvist followed Jonsson as CEO, and Mans Rosen filled the position in 2006. Kjell Asplund, Kerstin Hagenfeldt, and Nina Rehnqvist, in succession, followed Werko as chair.

\section{Board and Scientific Advisory Committee}

The Government appoints the Board Chair, the Chief Executive Officer, and a ten-member Board representing the clinical, scientific, management, and policy-making community in health. The CEO appoints a fifteen-member Scientific Advisory Committee representing different areas, for example, basic and applied medical research, clinical medicine, nursing, epidemiology, economics, management, administration, and public health.

\section{Selection of Topics}

SBU receives proposals for assessment projects from many sources, for example, individuals, organizations, governmental agencies, and other decision-making bodies. The SBU Scientific Advisory Committee also recommends topics for new projects.

The Ministry of Health may require SBU to conduct specific assessments. However, the Board generally the sets priorities regarding topics to be assessed. The criteria for prioritization among topics are as follows: (i) there must be enough scientific basis for an assessment; (ii) the topic must be of substantial importance to people's health and quality of life; (iii) it must concern many people, and/or be a common health problem, and/or have substantial economic, ethical, organizational, or human resource implications; and (iv) there should be some evidence of variations in practice.
The Board often gives priority to major areas in health care, including all technologies in use, for example, in the prevention, diagnosis, and treatment of alcohol and drug abuse, back pain, depression, obesity, hypertension, asthma, dementia, and chronic pain. For each area, all available technologies are identified and assessed.

\section{Working Procedures}

The SBU assessments include, in brief, the following: (i) a systematic review, based on well-defined protocols for inclusion and exclusion criteria and for grading evidence presented in all relevant studies in the international literature, that is, clinical studies, economic evaluations, and studies addressing other issues on the subject such as nursing, ethical, and social aspects; and (ii) a synthesis of the findings, including recommendations for health policy and practice.

A project is often preceded by a pilot study to determine what scientific evidence is available before the Board makes a decision about whether or not to start the project.

The systematic reviews are performed by groups of ten to fifteen people, including two to three staff members from SBU, all appointed by the Scientific Advisory Committee. At the start of each project the team participates in a seminar on critical assessment of scientific literature, and later the group runs several seminars to compare their grading of evidence and their findings. During its first decade, SBU had a close relationship with the Cochrane Collaboration, in particular with Andy Oxman, who ran training sessions for project teams for many years from the early 1990s.

The groups are composed of experts in the subject area studied. They do not work full time on a project. They receive no remuneration from SBU, but retain their salary from their employers, usually a County Council. Partly for this reason large projects often take 2 to 3 years to complete. The extended time it takes to finalize a project also reflects the fact that projects may cover twenty to forty different established and new technologies used in prevention and treatment of a disease area. Thousands of publications may need to be carefully scrutinized. For instance, SBU's report on back pain assessed approximately forty different technologies, and the report on radiotherapy in cancer assessed safety, efficacy, and effectiveness in relation to many different forms of cancer. The final reports from each project are published as books in one or more volumes; 400- to 600-page reports are not unusual. A separate summary and a targeted version for the general public are produced along with the reports. Before a report is released, several external reviewers scrutinize the manuscript.

In 1996, SBU developed a special program called Alert to rapidly assess (usually within 6 to 12 months) specific, mostly new, innovations in health care. Eventually, it became a collaborative program involving SBU, the Medical Products Agency, the National Board of Health and Welfare, and the Swedish Association of Local Authorities and Regions. 
SBU Alert has its own Advisory Board, who have extensive networks in many areas of research and with many institutions and colleges in health care. Individuals, organizations, or government agencies in Sweden and other countries may submit suggestions to SBU Alert regarding technologies to be assessed. The Advisory Board sets priorities of what to assess and appoints experts including SBU staff, to conduct the assessments. Target groups for SBU Alert publications include politicians and administrators, health services staff in decision-making positions at different levels, purchasers of medical devices and equipment, and the drug and therapeutic committees in different County Councils and hospitals.

In 1996, SBU was given a broader mandate and the resources needed to perform assessments in the field of dentistry. Similarly, in 2008, SBU received additional funds to perform more assessments in the field of mental health. Recently, the agency introduced two new on-line services; an information service (Upplysningstjanst for varden) to answer evidence-related questions from leaders of clinical services, and a new series (SBU Kommenterar) presenting information and comments on HTA's from other countries.

SBU regularly reports the results of all its assessments to the Ministry of Health and reports occasionally to the Committee on Social Affairs in the Swedish Parliament. An annual report, including finished projects and their impact on health policy and practice, and future plans, is submitted to the Ministry of Health. In reviewing the annual report, the Ministry may or may not suggest changes in SBU's plans with respect to the Government's healthcare priorities.

\section{Dissemination}

SBU quickly realized that efforts for effective dissemination and impact may be equally as important as producing scientifically reliable syntheses of research findings. Early on, a strategic decision was made to assure significant resources for these activities, including the following: (i) To reach all concerned stakeholders with a full assessment report. These stakeholders were individually identified for each topic: practitioners/clinicians managers, and local and national health policy makers. (ii) To develop summaries and special summaries targeted for the general public. These are distributed by means of the pharmacies throughout Sweden. (iii) To arrange press seminars and develop press releases on each project. (iv) To arrange local, regional, and national conferences and educational programs to present the results. (v) To develop a special program, the SBU Ambassador Program, in which interested clinicians who have participated in an SBU project are appointed as Ambassadors. They travel around in different counties to inform colleagues and other interested parties about SBU's findings. Recently, this program has been changed to designate "receivers" in each County Council, or in each region, ideally to be accountable for disseminating SBU findings. Regional centers for EBM have been established in four areas of the country. (vi) To pub- lish as many scientific papers as possible from each project. (vii) To translate all summaries and major reports into English. (viii) To develop and continuously update a vibrant and attractive Web site to effectively disseminate information from SBU. (ix) To develop a newsletter that describes ongoing projects, summaries of results from finished projects and related major studies published in scientific journals, interviews with prominent project members and members of the SBU Board and Scientific Advisory Committee, and interviews with other national and international figures in health care. This quarterly newsletter, named Science and Practice, has been produced from the start by Ragnar Levi and is distributed free of charge on a wide scale, approximately 12,000 copies per million population.

The results of SBU assessments are also communicated by means of the Journal of the Swedish Medical Association and in other national and international journals. News media in Sweden regularly report on the conclusions published by SBU. Its reports are also published in full text on the SBU Web site. Alert Reports are disseminated free of charge by means of an Internet subscription service.

SBU reports are frequently used as a basis for study materials, seminars, courses, and lectures. Conferences and clinical meetings are held in several locations to generate attention and initiate discussion about the reports. They are used in formulating national, regional, and local guidelines in health care, and are often used in recommendations from other agencies. The SBU project groups and networks of SBU Ambassadors across Sweden also initiate and promote local and regional efforts to help ensure that the reports are used by decision makers and that the findings are applied in clinical practice.

The wide representation of organizations and institutions on the SBU Board, and the many healthcare personnel who have participated in SBU projects over the years, help facilitate dissemination and impact. An estimated 2,000 people have been thoroughly trained in scientific assessments by lengthy participation in SBU projects. Actively attending team meetings over a period of 2 to 3 years, contributing through literature searches, surveys, and other research, writing chapters of a report, and reaching agreement on findings and conclusions all serve to create loyalty and dedication to the idea of EBM and HTA, which in turn facilitates dissemination and impact. Many more than those who have been active in SBU projects have been trained in EBM and HTA in Sweden.

\section{Impact}

SBU's impact is found predominantly in its significant contribution to evidence-based health care and HTA in Sweden, but to some extent also internationally. The establishment of SBU was soon followed by a wider movement in EBM and HTA in Sweden, and a few years later, the launch of the Cochrane Collaboration. EBM and HTA appeal very much to 
the rational Swedish mind, and these concepts rapidly permeated the whole of the medical and other health professions in the country. SBU's intentional and close collaboration with these groups, as well as with other agencies and institutions in the field of health care, also played a role in expanding the movement.

For approximately 10 years, SBU annually evaluated its potential impact through large-scale surveys of policy makers, managers, and the medical profession. These surveys showed a steady and rapid increase in the awareness and use of results from SBU assessments. Ten years after its inception, SBU was well known by an overwhelming majority of the medical profession, who also reported using the results of the assessments in their daily practice.

Considerable evidence shows the impact of specific SBU assessments, particularly their impact on disinvestment. From the outset, the Government's mandate for SBU included a concern about effective allocation and utilization of resources. Although, it did not explicitly mention disinvestment, several of SBU's projects seriously questioned the value of certain technologies or practices and produced cost savings from findings that certain interventions are without benefits and should be eliminated from clinical practice.

The first study by SBU, published in 1989, focused on the costs and benefits of preoperative routines. It concluded that routine testing in elective surgery of younger and otherwise healthy patients with no medical indications for the tests were of limited or no benefit to the patient, the anesthesiologist, or the surgeon. In addition, such tests could lead to substantial harm from false positive findings and further invasive procedures. The impact of these findings was immediate. A study examined routine testing in a large sample of patients (nearly 4,000) before the report was released. The study was repeated 1 year and 3 years after the report was published and showed a continuous, rapid decline in the use of routine preoperative testing. The decrease represented yearly savings in direct costs of around 30 million USD, or ten times the SBU annual budget at the time (5).

The SBU study on back pain demonstrated that many of the technologies or procedures used to treat this syndrome were not supported by scientific evidence (18). Instead, several frequently used strategies, for example, sick leave, bed rest, and other inactivating practices, were actually contraindicated and did more harm than good for the patient. These findings, comparatively new as they were at that time, changed the attitude about the problem-away from medical and surgical interventions and inactivity toward staying active and trying to cope also with the psychosocial aspects of the syndrome. These views were incorporated in the Government's reform of the social insurance system in the early 2000s and a dramatic reduction in the rate of sick leave due to back pain followed the publication of this report.

An assessment addressing the treatment of mild hypertension showed that diuretics and beta-blockers not only are approximately half as expensive as the new drugs, but also are equally effective in lowering blood pressure and reducing mortality and morbidity. SBU published those findings over 10 years ago, and they have since been confirmed in numerous studies published in the scientific literature. Statistics show that prescriptions for the newer drugs decreased considerably in Sweden after publication of the study, while concurrently prescriptions for the older drugs increased. These tendencies were not observed in many other countries (4).

A comprehensive assessment of technologies used in treating depression showed, among many other findings, that light therapy does not have a scientific basis for its effects in patients with depression. Gradual disinvestment in this practice is being observed (24).

An assessment of bone density measurement concluded that there are no compelling scientific reasons to include bone density measurement as part of general or opportunistic screening. The volume of new equipment purchased for this purpose decreased substantially after the report was released (23).

SBU's study on the effectiveness of technologies used to treat alcohol and drug abuse demonstrated that resources spent on unstructured support programs, approximately half of the total resources spent in this area, either lack evidence of benefits for patients, or are scientifically proven to be useless for patients' recovery (21).

A recent SBU report on treating osteoporosis found no scientific evidence to support the prescription of calcium or vitamin D to women under the age of 80 years. In Sweden, the potential annual savings from an altered practice in treating osteoporosis is estimated at 5 million USD $(8 ; 22)$.

A randomized trial performed by SBU on CT versus hospital admission for patients with mild head injury found no advantage for in-hospital observation versus immediate CT and discharge to home for patients with no signs of trauma. That study also demonstrated that the new strategy for CT could reduce costs by one-third without a negative impact on patients. That would represent direct cost savings of 5 million USD per year $(10 ; 19)$.

It takes at least a few years to measure the impact of an HTA, if indeed possible at all. However, considering the strong impact that SBU has had on clinical practice in Sweden, it is feasible that direct cost savings of around 10 million dollars per year may be achieved when the new practices come into effect from the findings on treating osteoporosis and the findings on CT versus hospital admission.

The examples above represent only part of the agency's impact, which is by no means restricted to cost savings alone, but also to increased safety and improved quality of care. For example, the SBU reports on depression and on alcohol and drug abuse have increased the prescription of more effective pharmaceuticals for these disorders $(3 ; 24)$.

SBU's report on the use of neuroleptics demonstrated that these drugs should not be prescribed for elderly patients, except in cases of psychosis and even then only in low doses. It was also shown that, in people with dementia, 
neuroleptics do not have better effects than placebo, but may produce serious side effects. The prescription of neuroleptics in higher doses decreased almost immediately after publication of SBU's report. This did not necessarily result in cost savings, but improved the quality of care in terms of less suffering, anxiety, and pain and a lower risk of serious irreversible side effects (24).

\section{International Collaboration}

Even before SBU was established, many, if not all, of the people who came to play an important role in the organization had individually built up an extensive international network of researchers in many fields, some of which included HTA. Unquestionably, international collaboration was a natural part of SBU's agenda from the outset, and still is. SBU's early strategy to disseminate its findings in English helped position it to take a leading role as the HTA community developed internationally. Producing material in idiomatic English required the translation and writing skills of a native speaker with knowledge of HTA. This task fell to Ron Gustafson, a medical writer who had reviewed new technologies, for example, CT scanning and open heart surgery, for the Health Planning Council in Madison, Wisconsin, during the late 1970s.

When Iain Chalmers in the UK started the Cochrane Center in 1989, later extended to the Cochrane Collaboration in 1992, the CEO and Board Chair of SBU visited him to discuss collaboration. This resulted in a substantial and appreciated commitment from SBU to financially support the Cochrane Collaboration for a 3-year period (6). The impetus for this from SBU was that the establishment of the Cochrane Collaboration would become an invaluable resource in performing systematic reviews, which at that time was a comparatively difficult task.

SBU was one of the founding members of the International Network of Agencies in Health Technology Assessment (INAHTA) in 1993. The secretariat of INAHTA was initially located at the Canadian Coordinating Agency for Health Technology Assessment, CCOHTA, later known as CADTH. In 1996, the secretariat moved to SBU and has remained there since that time.

Over the years, SBU has hosted many individuals from other countries as trainees or project members. To mention a few of those known in the HTA community; Cliff Goodman, who did a pioneering report on literature searching and evidence interpretation at SBU (11), Mark Fendrick (now Editor of Managed Care) and Deborah Marshal, now professor at the University of Calgary, all worked at SBU for several years. In the 1990s, SBU undertook a major project on appropriateness in cardiac care, working in close collaboration with Robert Brook and colleagues from the Rand Corporation (23). Many other researchers from throughout Europe and from the US have participated in SBU projects.
SBU has been heavily involved in several large-scale projects at the European level, financed by the European Commission. Notably the so-called EURO-ASSESS (2), and the ECHTA project, European Collaboration for HTA (15).

SBU is a technical member of the WHO Health Evidence Network (HEN) and, through INAHTA, a WHO Collaborating Center for HTA. SBU is also an active member of Euroscan.

The Editorial Office of the International Journal of Technology Assessment in Health Care was shared between the University of Texas (Stanley Reiser) and SBU (Egon Jonsson and Christina Engstrom) from 1987 to 2003.

\section{Criticisms}

The picture painted here of SBU is bright and positive; a story of success. The yearly assessments by the Government and the independent assessment mentioned above of SBU's performance and impact show similar findings (28). Thus far, the agency has been truly prosperous and is appreciated, trusted, and held in high respect by most people at all levels of the healthcare system in Sweden. An important factor supporting its achievements, in addition to those mentioned above, is that it was launched at the very beginning of the international quest for EBM. In addition, SBU is organized around Sweden's history and tradition of working in transparency, collaborating with as many stakeholders as possible, and trying to reach out to the interested general public with its findings.

However, SBU has also been criticized on several aspects of its work, some of which it cannot control.

SBU has paid relatively little attention to issues that are of great concern to the general public, namely waiting times, and to issues of access to care. To some extent, it would seem feasible to address such issues in HTAs, as well as to issues of funding, including potential fee systems for different technologies.

The extended time it takes for SBU to complete many assessments is a source of concern and critique from many in the international HTA community. SBU itself is not particularly concerned about the fact that many projects take 2 to 3 years to complete, sometimes even longer, in view of the benefits. SBU does not remunerate people for working on its projects. Hence, it must adjust to the normal working schedules of the participants. Furthermore, SBU views participation in its projects as a major learning opportunity, which generates ambassadors to disseminate its messages. Except for the Alert program, SBU generally does not assess a single technology at a time, but all technologies surrounding a specific health problem-often including prevention, diagnosis, and treatment and always including both established and new technologies. By definition, this process is much more time-consuming. However, it also has a major advantage; namely that such a comprehensive and broad-based review of all options provides policy makers and 
practitioners with a basis to consider the appropriate dissemination and use of a technology.

It has also been argued that SBU's impact, although indisputable and significant, is far less than it might have been, and that the agency lacks real power to link research findings with health policy and practice, particularly with regard to funding of services. This is a valid critique, however; the agency has no regulatory function. SBU would not necessarily fulfill its mission much better if it had such a function, because regulatory actions must be placed in a much broader and more context-specific perspective than findings from research alone. SBU is currently in the process of enhancing its impact through closer collaboration with several agencies that have regulatory and monitoring functions. Findings from SBU assessments are currently used in developing national guidelines by the NBHW and the Medical Products Agency.

SBU may have failed in handling new innovations at an early stage, despite the Alert program, and especially with regard to new, costly, rapidly diffusing technologies such as percutaneous coronary intervention and stents, and new pharmaceuticals (16). Assessment of pharmaceuticals has not been a priority at SBU, because the Medical Products Agency in Sweden has a mandate to assess the safety, efficacy, and effectiveness of drugs. However, an important issue for HTA generally is the appropriate indications for use. Although SBU has focused its assessments on that issue in a few projects on pharmaceuticals, it may want to consider further efforts in this regard.

\section{FUTURE OF HTA IN SWEDEN}

Innovations from research will continue to provide health services with new and promising technologies. As long as a patient might benefit from the use of a technology, it will generate a strong demand-not only from patients, but also from the media, the public, and the healthcare professions. It is widely recognized that diffusion and use of health technology is the major force driving the increasing cost of health care. Although controlling increasing costs is an extremely important issue, even more important questions are: What is the value for money of new innovations, and are emerging technologies worth the investments required?

This is a complex question to address. It requires knowledge not only about the medical aspects of a technology, but also about much broader and deeper ethical, social, and economic implications than those usually dealt with by HTA today. It also requires even broader comparative effective analyses and analyses of innovations in the delivery of care, particularly for chronic diseases, and optional funding of services, including management and organizational issues.

The Government may be able to use different types of regulations to control, at least in part, the development and use of health technology. It can regulate through measures like accreditation procedures, quality assurance, guidelines, prospective payment mechanisms, capitation payment schemes, pay per performance, health planning, and other tools. In theory, several measures will create incentives to make use of more cost-effective technology. In reality, some of these work to a certain extent, but most systems easily become either too complicated or too simple to deal with the complex implications of rapid technological advances in medicine. In the absence of powerful measures to limit overall healthcare spending, and to balance technological advances with available resources, HTA is likely to increase in importance as a means to assist health policy making and clinical practice.

Some evidence on this is found in the fact that both the federal government and many County Councils have increased their financial support for HTA in Sweden. Nevertheless, it is still remarkably low in relation to what would be needed to reduce ineffective practices and achieve truly effective healthcare delivery. The increased collaboration that now is taking place between actors, institutions, and agencies on the subject of assessing health technology is another sign of its increasing importance. Hopefully, it will be possible to bridge research findings with action and some form of managerial and professional accountability in applying evidence. Stronger, perhaps economic, incentives seem to be necessary to squeeze evidence into the processes of all the urgent priorities that policy makers and practitioners must constantly deal with on a daily basis. Bengt Jonsson has formulated this concern as follows:

The single most important issue related to efficiency and quality, as well as cost-containment, at present is the introduction of new, and often expensive, medical technology. This is a management problem, but also an issue with wider implications for health policy. In the end, it is a question about how much a nation can afford and choose to spend on health care, and about incentives for investments in medical research to develop new treatment opportunities. It is an issue with national as well as international implications, and there is also a link to the development of the biomedical industry as a source of economic growth in a country... . HTA will probably rise to be the most important policy instrument, because it can help making the "great trade-off" between static and dynamic efficiency, to provide optimal incentives for innovation, while controlling costs. But that requires that politicians governing the county councils fully embrace the principles of open priority setting, and that managers and leading clinicians at the hospitals take a leadership in implementing them (17).

\section{CONTACT INFORMATION}

Egon Jonsson, PhD (ejonsson@ihe.ca), Professor, University of Alberta, and University of Calgary, Editor-in-Chief, International Journal of Technology Assessment in Health Care; Executive Director \& CEO, Institute of Health Economics, \#1200, 10405 Jasper Avenue Edmonton, Alberta T5J 3N4, Canada 


\section{REFERENCES}

1. Anderson OW. Health care: Can there be equity? The United States, Sweden, and England. New York: John Wiley and Sons; 1972.

2. Banta HD. Introduction to the EUR-ASSESS report. Int J Technol Assess Health Care. 1997;13:133-143.

3. Britton M, Asplund K, Brorson B, et al. Sa paverkade SBU praxis i varden. Konsekvenserna av sju rapporter granskade. Lakartidningen. 2002;99:4628-4634.

4. Britton M, Jonsson E. Impact of health technology assessments. Int J Technol Assess Health Care. 2002;18:824-831.

5. Brorsson B, Arvidsson S. The effect of dissemination of recommendations on use. Preoperative routines in Sweden 1989-91. Int J Technol Assess Health Care. 1997;13:547552.

6. Cochrane.org search. Chronology of the Cochrane Collaboration. http://www.cochrane.org/docs/cchronol.htm.

7. Förordning (2007:1233) med instruktion för Statens beredning för medicinsk utvärdering. https://lagen.nu/2007;1233 (accessed December 2007).

8. Freyschuss B, Ljunggren O, Saaf M, Mellstrom D. Behandling minskar frakturrisk hos kvinnor over 80 ar-men inte hos yngre. Lakartidningen. 2007;104:858-859.

9. Gaensler E, Jonsson E, Neuhauser D. Controlling medical technology in Sweden. In: Banta HD, Kemp KB, eds. The management of health care technology in nine countries. New York: Springer; 1982:167-192.

10. af Geijerstam JL, Oredsson S, Britton M; OCTOPUS Study Investigators. Medical outcome after immediate computed tomography or admission for observation in patients with mild head injury: Randomised controlled trial. BMJ. 2006;333: 465.

11. Goodman C. Literature searching and evidence interpretation for assessing health care practices. SBU report. Stockholm: SBU; 1993.

12. Hillborg I. Socialnytt petitanummer. Stockholm: Socialstyrelsen; 1981.

13. International Workshop on Evaluation of Medical Technology. Swedish Planning and Rationalisation Institute of the Health Services. Stockholm: Spri; 1979;3089:1.

14. Jonsson E. Studies in health economics. Stockholm: Stockholm School of Economics; 1980.
15. Jonsson E, Banta HD, Henshall C, Sampietro-Colom L, eds. Report of the ECHTA Project. Int J Technol Assess Health Care. 2002;18:171-183.

16. Jonsson E, Banta HD. Health care technology in Sweden. In: Banta HD, Gelband H, Jonsson E, Battista R, eds. Special Issue: Health care technology and its assessment in eight countries: Australia, Canada, France, Germany, Netherlands, Sweden, United Kingdom, United States. Health Policy. 1994;30:1-421.

17. Jönsson B. Cost Containment in Sweden. In: Rapoport J, Jacobs $\mathrm{P}$, Jonsson E, eds. Cost containment and efficiency in national health systems: A global comparison. New York: Wiley/Blackwell; 2008.

18. Nachemson A, Jonsson E. Neck and back pain: The scientific evidence of causes, diagnosis, and treatment. Philadelphia: Lippincott, Williams and Wilkins; 2000.

19. Norlund A, Marke LA, af Geijerstam JL, Oredsson S, Britton M; OCTOPUS Study. Immediate computed tomography or admission for observation after mild head injury: Cost comparison in randomised controlled trial. BMJ 2006;333:469.

20. Porter D. Health, civilization, and the state. New York: Routledge; 1999.

21. Rehnqvist N, Marké L-Å. Kan inverkan av evidens matas? Stockholm: SBU; 2006.

22. SBU. Behandling med vitamin D och kalcium. Stockholm: Statens beredning for medicinsk utvardering (SBU); 2006. SBU-Rapport nr 178.

23. SBU. Coronary artery bypass graft and percutaneous transluminal coronary angioplasty. Stockholm: SBU; 1994.

24. SBU. Kunskapscentrum for halso-och sjukvarden: En strategi for SBU aren 2007-2010. www.sbu.se (accessed January 2009).

25. Socialstyrelsen. Historia. http://www.socialstyrelsen.se/Om_ Sos/Historia/Collegiummedicorum.htm.

26. Socialstyrelsen. Svensk medicinalhistorisk bibliografi (MEDORG). http://www.medorg.scb.se/.

27. Spri. Magnetic resonance imaging: Issues of costs and benefits. Stockholm: Spri; 1984.

28. Utvardering av SBU (Holgersson B et al., Chair) Slutbetankande av SBU-committen. SOU 1991:6.1.

29. Socialdepartementet. Vårdens svåra val. Statens offentliga utredningar (SOU). Stockholm: Socialdepartementet; 1995.

30. Slutbetänkande av Prioriteringsutredningen (Einhorn J. et al., Chair) Stockholm. 1994. Available in English. 